\title{
SMALL IS BEAUTIFUL: THE RE-EMERGENCE OF THE CONVENIENCE STRATEGY
}

\author{
Richard Metters \\ Southern Methodist University \\ Dallas, TX \\ Michael Ketzenberg \\ University of North Carolina - Chapel Hill \\ Chapel Hill, NC
}

\begin{abstract}
For much of the last few decades it has appeared canonical that "bigger is better" in the physical size of retail stores. In practice, the grocery and general merchandise categories have seen tremendous increases in average store size. Academic literature points to many benefits of size. Advances in information technology and logistics, however, have provided a platform for a cost and quality competitive small store format. The viability and strategic functional choices of the small store, "convenience" strategy is explored.
\end{abstract}

\section{Introduction}

Service sector strategies involving facility size and location have changed drastically throughout this century. Prior to the widespread use of automobiles for shopping in the U.S., retail outlets such as grocers, banks, and general merchandise stores had to be physically close to the customer. The more primitive business practices than seen today also limited store size. Many service sector firms did not keep even rudimentary accounting records, the logistics of procuring a large variety of goods and coordinating deliveries was difficult, and assortment and inventory decisions were complex enough so that the average drug store stock turned an average of only three or four times a year in the 1920s (Strasser \& Tedlow, 1994). Consequently, the additional complexity of increasing size could create diseconomies of scale.

More recently, smaller numbers of ever-larger stores have been in vogue. For example, in the grocery industry the market leader in 1929 was A\&P, with 15,738 stores that averaged 1,134 sq. $\mathrm{ft}$., and the three market leaders combined for nearly 24,000 stores (Strasser \& Tedlow, 1994). No individual firm in the industry today has more than 3,000 stores and the average store size is $29,092 \mathrm{sq}$. ft. (Sansolo \& Garry, 1994). Further, the stated policies of today's market leaders is to increase the ratio of "superstores" of 50,000 sq. ft. (Kroger 1997; Strasser \& Tedlow, 1994), so average store size should continue to increase.

This effect has not been limited to the grocery industry. The market leader in general merchandise, Wal-Mart, has seen average store size increase over $30 \%$ to 92,000 
sq. ft. from 1990 to 1997 , and is increasing the ratio of Supercenters which measure over 200,000 sq. ft. (Lee, 1998). In terms of number of outlets, however, Wal-Mart pales with prior market entities: Wal-Mart's 2,500 stores may seem ubiquitous, but the 16,000 U.S. stores in the American Druggist Syndicate in 1913 must have been on every street corner (Strasser \& Tedlow, 1994).

The strategy of large stores has extensive support in the academic literature, which will be reviewed in the next section. Our thesis, however, is that the combination of improved business practices, specifically the technical improvements in information systems and operational logistics and inventory advances, combined with increased consumer desires for convenience, has created an environment where networks of small stores can become a dominant paradigm once again.

Certainly, a strategy of small stores focused on locational convenience has always been available, but with substantially higher costs and lower quality. A number of firms compete in that manner, such as Jacoby \& Myers for legal services, H\&R Block for tax preparation, or MotoPhoto (one hour film developers) for film developing.

We argue that conditions have changed sufficiently that, done appropriately, a small store convenience strategy can be competitive on these other issues. Current examples of firms that are cost and quality competitive, yet focus on a convenience strategy are: Dollar General (a competitor of WalMart, and opening 500 new stores per year) (Berner, 1998); a revamped Southland Corporation (expanding by 300-400 new 7-11 stores per year) (Lee, 1998); Edward D. Jones, a stockbrokerage headquartered in St. Louis with 4,570 offices in the U.S., Canada and England, typically manned by a single broker; and National Commerce Bankcorporation, where $85 \%$ of the retail bank branches are mini-branches within supermarkets and are manned by only two or three employees at a time.

Moreover, we contend that a small store strategy cannot simply be "grafted on" to a chain of large stores. The small store/convenience strategy has a coherent set of operational, marketing and human resource policies that are in conflict with those of large stores.

After reviewing the fundamental arguments in favor of large stores, we present the basic arguments for small stores. Subsequently, we recommend the different approaches that should be taken by small stores by various functional areas.

\section{Arguments for Size}

The strategy to increase store size has extensive support in the academic literature. This support comes from two directions: marketing research that indicates large stores are more attractive to customers and operations oriented work concerning cost reductions with larger size. 


\section{Customer Attraction Models}

Research suggests that the observed growth in store size in the grocery sector is a response to increased demand for one-stop shopping (Messinger \& Narasimhan, 1995; 1997). Larger stores are presumed to have greater category variety, thereby reducing the need for the number of shopping excursions.

Mathematical links between store size and customer attraction are seen in the facility location literature in gravitational models. The relationship between store size and customer attraction is typically quantified by an objective function that maximizes sales with store size as a model parameter. Gravity models are an analog to the gravitational attraction in physics, where attraction is proportional to the product of their masses and inversely proportional to the distance that separates them. For example, from Fitzsimmons and Fitsimmons (1994) we have $A_{i j}=S_{j} / T_{i j}$ where $A_{i j}=$ attraction to facility $j$ for consumer $i, S_{j}=$ size of facility $j, T_{i j}=$ travel time from consumer $i$ 's location to facility $j$, and 1 reflects the effect of travel time on various kinds of shopping trips (e.g., where a supermarket may have a $l=2$, convenience stores would have a larger value). In such a model, the larger the facility - or the more variety it holds - the more attractive it becomes. Grocers, for one, have heeded this advice, increasing the number of different items stocked in the average supermarket from 6,000 in 1960 to over 18,000 in 1993 (Samsolo \& Garry, 1994).

\section{Cost Reduction and Scale Economies}

Cost reductions accrue to larger facilities in both personnel and inventory due to variance reduction. For inventory oriented services such as clothing stores, general merchandise and grocers, the textbook theory is that less overall inventory needs to be carried in a centralized system. Comparing a system of smaller stores to one large one with the same aggregate demand, the mathematics of how much inventory to carry benefits the single large facility according to the "square root" law of combining demand distributions (Levy, Zinn, \& Bowersox, 1989; Moinzadeh \& Ingene, 1993). As a numerical example, consider demand distributed according to a normal distribution with mean 100 and standard deviation 25 $[\mathrm{N}(100,25)]$ for each of 10 stores. Safety stock of 10 stores $\times 25 \times 1.65=413$ units would be required for a $95 \%$ service level for each store. If the demand for all 10 small stores were concentrated in one large store the demand distribution would be $\mathrm{N}\left(1000,25^{*} \operatorname{sqrt}(10)=79\right)$, requiring only $79 * 1.65=130$ units of safety stock to achieve a similar level of service.

For services where inventory is not important, such as banks, barbers or travel agencies, similar savings can also be had in personnel staffing using the concept from waiting line theory that a single queue (or service pooling) is more efficient than multiple queues when serving the same population of customers. The specific numerical calculations are different, but the well known result is the same when it is applied to large versus small stores: a single large store, drawing an equal number of 
customers as many small stores, requires fewer overall workers to achieve the same service levels.

\section{Arguments for Convenience}

Certainly, locational convenience is a strategy unto itself, regardless of other factors. So-called "convenience stores" have existed for some time. Other services also find locational convenience to be highly important. For example, a Bank Administration Institute survey found that a convenient location was the most significant factor of consumer choice of financial institutions, cited by $60 \%$ of respondents.

The traditional model of a convenience store stands as a model of a trade-off: convenience is attained, but at the price of higher costs, lower service and lower quality. The model we are proposing is to attain convenience while remaining competitive on other strategic points. In the remaining sections we focus on functional policies to enact this. First, however, we discuss the deficiencies inherent in the preceding arguments for large units.

\section{Customer Attraction Models}

The customer attraction models presented earlier suffer from two main flaws: a lack of consideration of the disutility of large stores and a lack of competitive effects in these models.

For large stores, customers usually have a longer walk from a parking area to the store entrance and search costs in the store itself are higher than small stores. Although obvious, these considerations do not appear in the customer attraction models.

Also, the attraction models are used in isolation and do not consider a competitive environment. Given the attraction model cited earlier, $A_{i j}=S_{j} / T_{i j}^{i}$, the probability of a customer preferring one store over another is given as a ratio of each individual store's attraction level to the total attraction level of all stores (Fitzsimmons \& Fitzsimmons, 1994). Consequently, if a large store and a small store were an identical distance away from a customer, the large store would be preferred with a high probability. However, this misses the point of the convenience strategy, where the premise is to establish a network of stores in a given area. Consequently, the vast majority of consumers will have a smaller travel time $T_{i j}$ to the smaller stores, balancing out the attraction of size.

As noted by a Wal-Mart executive, "(w)e lose customers because the supercenter is too busy and not convenient" (Lee, 1998). One of the firms Wal-Mart is losing customers to is Dollar General. Dollar General has over 2,000 stores in the Southeastem U.S., and is opening stores at a rate of 500/year. Their strategy is to battle each 92,000 sq. ft. store of Wal-Mart with a platoon of 6,000 sq. ft. stores (Berner, 1998). Dollar General benefits from both of the aspects mentioned above. It is physically closer to far more customers than a Wal-Mart, and it takes far less time to park and shop at a Dollar General. The convenience aspect is so strong that Dollar General often locates 
adjacent to a Wal-Mart or other similar competitor. This can be successful because Dollar General can match Wal-Mart on price - it has a far lower operating cost per square foot than Wal-Mart (Berner, 1998).

\section{Cost Reduction and Scale Economies}

Presence of size for attaining scale economies is a seemingly logical argument, but empirical studies have not agreed. Past empirical studies of the grocery industry indicate that the growth in supermarket size has gone well above the minimum size required to take advantage of scale economies. Most studies show increasing returns for small levels of operation, but show constant, or decreasing, returns for large levels of operation (Douglas, 1962; Good, 1984; McClelland 1962; Tilley \& Hicks, 1971). Increasing returns appear to be exhausted in the range from 7,000 to 10,000 sq. $\mathrm{ft}$. one-third the average store size. Ratchford and Brown (1985) reach corroborative conclusions that total factor productivity in the industry has remained constant or declined since 1979, when supermarket size began to accelerate. The most recent of these studies concludes that returns to scale is an insufficient explanation to the growth in store size (Shaw, Nisbet, \& Dawson, 1989).

The cost reduction arguments proffered earlier also contain assumptions that may not hold or can be overcome in many cases.

The "square root law" applied to inventory reduction holds in its pure form only when the demand is independent between stores. At the extreme, if the correlation of demand is one between stores, there would be no safety stock benefit whatsoever from having one large store. In the small geographic areas that we are concerned with, it stands to reason that demand correlations could be very high, though data must be analyzed for any particular business to determine if this indeed is the case. For example, demand variance that is unpredicted by a store can be caused by weather. On a day that it rains, more umbrellas are sold. When pollen abounds, hay fever medicines sell. These events tend to occur throughout the entirety of a small geographic area simultaneously, so the advantages of one location are small.

Further, this inventory model assumes periodic resupply. That is, it assumes that resupply comes from a distribution center once a day or week or month, and that emergency resupply is prohibitively costly. Consequently, if an out-of-stock condition exists, it necessarily causes lost sales or backorders until the periodic order comes in. However, this does not have to be the case with a convenience strategy. Because they are physically located close to each other, units can easily send either stock or employees to each other at little cost, bypassing the normal route of the distribution center. Of course, a cost will still be incurred even in very close store-to-store transfers, and the relative costs of store-to-store versus distribution center-to-store transfers have not been carefully examined by any of the firms known to the authors who pursue this method.

The results from traditional queuing models seem to strongly indicate that, overall, more employees will be needed in a small store network than in one large store to 
handle the same number of customers with the same service level. This logic, however, has two implicit assumptions that may not be true: that time not spent with customers is unproductive and that employees must be physically located at the same site the customer visits.

Queuing theory dictates that a multiple small store strategy requires a higher amount of idle time for the same service level as a large store. But this measure of idle time only reflects random customer arrivals. For all the activities in a service business that require the presence of a customer, there are also many activities which can be completed without a customer present. The traditional service sector logic presented by Chase $(1978 ; 1981)$ indicates that such back-office activities should be segregated from front-office, customer oriented activities and performed by different, back-office workers away from the view of customers. To achieve reasonable costs, however, a convenience strategy firm should move enough of the back-office activities to the frontoffice to avoid excessive idle time.

As an example of such a firm, the National Bank of Commerce has $84 \%$ of its branches in grocery stores (Williams, 1997). These branches are much smaller than a typical bank branch, with only $400 \mathrm{sq}$. ft. of space and usually staffed by only two or three employees at a time and have a deposit and customer base much smaller than a traditional bank branch. Their big bank competitors have backoffice personnel not located in branches who conduct such work as credit checks, employment verifications and document preparation. At the National Bank of Commerce, however, all these functions are performed by tellers at the branch during downtime between customers.

Lastly, with advances in technology, a network of stores does not necessarily mean a network of employees. At such large banks as Mellon Bank and First Union, walk-in customers who wish to open an account or have a question are steered to video displays and phone banks. The bank employees at the other end are located, of course, in a central facility that can staff in accordance with the queuing benefits achieved by pooling demand.

\section{Recommendations for Implementation}

Traditionally, small store formats and back-office support are set up with only convenience in mind. Alternatively, large store formats and back-office support are set up to rely on the benefits of size discussed earlier. It is our position that, in order to succeed in a small store format at providing quality, flexibility, and low costs in addition to convenience, a different set of choices must be made for each functional area than in firms that focus on a large store strategy or in firms that focus solely on convenience. Further, because of the conflicting sets of strategic parameters that are required, it is unwise to "graft on" a series of small stores to the back-office support structure of a predominantly large store firm. 


\section{Operations and Information Systems}

A major operational challenge for inventory-oriented services is to ensure that a small store does not equate to a small selection of goods. Certainly, a 1,500 sq. ft. 7-11 cannot have the breadth of selection of a $29,000 \mathrm{sq}$. ft. grocery store. But given tightly linked information systems and just-in-time logistics support, it can come close.

Largely, the vast inventories seen today in large retail stores are unnecessary. Industry-wide in the grocery industry, an average of 26 days of inventory of dry grocery items is on display (Kurt Salmon Ass., 1993), despite the fact that dry goods are typically resupplied 4-5 times per week. An analysis of a typical dry grocery category by the leading trade journal cited inventory levels on display at 49 days of inventory (Thayer, 1991). There is evidence that European grocers stock at similar levels (Fernie, 1995). The industry is aware of this problem, and many have adopted what they term "Efficient Consumer Response" as a central organizing principle to get inventories throughout the supply chain under control, but progress has not been swift.

This is not industry specific, however, as inventories throughout the retail sector are often set at seemingly extreme levels. Anecdotally, inventories of cosmetics at department stores often turn over twice yearly (Seshadri, 1996) and retail clothing stores attempt to set inventory levels at $100 \%$ service levels by stocking several weeks of demand (Agrawal \& Smith, 1996).

One of the reasons for such overstocking is poor systems integration. Although all major grocers use scanner technology at cash registers, to date only one chain is using scanner information to order stock or pay suppliers, and only in a few trial stores (Austin \& McFarlan, 1997). Stock ordering is still done manually by employees visually checking shelf sets. Further, information systems are not fully utilized for forecasting, and quantities ordered and quantities sold are not highly correlated. It is often the case that retailers order mounds of slow movers while keeping slim inventories of fast selling products. This is an all too common problem in the grocery industry, where $56 \%$ of dry grocery items average less than one unit in sales per week (Kurt Salmon Ass., 1993).

Tightly linking information systems with inventory needs can even be done centrally. In the late 1980's Mrs. Fields' Cookies electronically linked all 500 stores to computers in Park City, Utah, and the managerial decisions concerning not only supply ordering but hour-by-hour demand forecasting which cookies to make at different points throughout the day were performed centrally (Ostrofsky \& Cash, 1993). Part of the revitalization of the 7-11 brand, where massive store closings in the 1980's have tumed into equally massive store openings now, has been a tightly linked inventory information system that is coupled with good logistic support for inventory resupply.

Large stores can afford the inefficiencies of poorly linked information systems and inventory positions more easily due to the traditional impact of diminishing returns. Whereas the impact on consumer preferences in a large store between stocking 18,000 
versus 20,000 different items may not be large, customer attraction for a small store stocking 5,000 versus 3,000 different items is likely to be highly significant.

\section{Human Resources: Job Design and Reward Systems}

By nature, small stores have few employees. Consequently, each employee must be able to perform a wide range of tasks. This places a higher premium on small stores for cross-training. Since greater training is invested in each employee, employee retention is more important at such firms. Further, as discussed previously, more back-office tasks have to be performed by front-office personnel in small units than in large ones to off-set the higher customer related idle time that occurs in small units.

This makes job design at a small unit vastly different from its larger counterparts. This design, however, has advantages. It is generally believed that internal motivation, job satisfaction and effectiveness are linked to the knowledge of the results of work activities, the degree to which a task seems to be an identifiable unit and the responsibility that an individual feels for the outcome of their work (Hackman \& Oldham, 1980). Being responsible for an entire process assists in seeing duties as an identifiable unit and thereby have a more intrinsic motivating influence.

This has direct ramifications regarding service quality. The traditional structure of segregating tasks does not lend itself to accommodating the customer. Front-office personnel may only see the customer. In the banking industry, customer information often is sent electronically or faxed to a geographically distant centralized unit where the next available person takes the work. The front-office personnel never meet nor even know the names of the back-office workers. Similarly, the back-office workers never see either the customers or the front-office workers. Because of this, the front-office worker may develop empathy with the customer, but the front- and back-office workers may not develop camaraderie within the company. This can lead to two related problems. Primarily, front-office workers may make reasonable special requests that the back-office workers are not anxious to fulfill. Back-office workers typically are rewarded on production, and special requests slow down the process, so they are less likely to accede to special circumstances. Conversely, front-office workers may be willing to promise customers anything to get their business, even if they are aware that the backoffice cannot provide the service. The front-office worker thereby appears to give good service to the customer on the front end, and when the service is not delivered appropriately, blame can be shifted to the back-office facility.

Reward systems in a network of small stores also should consider the larger network. In a small store network there are advantages to be gained by sharing personnel, local information, and inventory imbalances. Reward systems should be structured so that personnel are looking for ways to contribute to the network, rather than just reacting to requests. 


\section{Marketing}

For non-inventory oriented services, the fact that personnel have to learn a greater variety of tasks makes it difficult to have a broad, complex product line. For example, the small branch banks mentioned earlier typically do not handle corporate loans. The one-person stock brokerages of Edward D. Jones do not sell derivatives or penny stocks. Front-office information systems can be extremely useful is this respect. Due to the employees already being stretched by having to perform a wider range of processes, product development should be accompanied by very easy to use software with highly scripted service encounters.

For many of the larger service firms where tasks are segregated and the unit is a collection of specialists, one of the specialties can be customer generation. For example, in many large banks the only task a loan officer has is to generate loan applications. They are expected to join local organizations and reach out into the community to attract demand by force of personality. For small units, however, the loan officer is also a teller, a bookkeeper, etc., and they are not expected to become prominent members of the community. Consequently, the task of generating customers is up to a centralized marketing department.

\section{Summary}

A strategy of smaller, more numerous and convenient services was a dominant strategy at the beginning of the 1900's. But the reason for this dominance was customer immobility and corporate inability to deal effectively with large scale organizations. We believe this strategy can once again become a dominant force, but for entirely different reasons. Information systems and logistics have advanced to the point where the goals of quality, cost and flexibility can be achieved in small units, and customer intolerance of the inconvenience of large units is increasing due to demographic changes.

Small units, however, must be managed appropriately to be successful. Due to the structural differences between small and large units, it would be difficult for a system of large units to simply add-on a network of small units. Human resource policies, marketing challenges and the relationship between front-office and back-office personnel can be very different between such organizations.

\section{References}

Agrawal, N., \& Smith, S. (1996). Estimating negative binomial demand for retail inventory management with unobservable lost sales. Naval Research Logistics, 43, 839-861.

Austin, D., \& McFarlan, F. (1997). H.E.Butt Grocery Company: A leader in ECR implementation (B). Case 9-198-016, Cambridge, MA: Harvard Business School Publishing. 
Bemer, R. (1998). Penny pinchers propel a retail star. Wall Street Journal, March 20, 1998, B1.

Chase, R. (1978). Where does the customer fit in a service operation? Harvard Business Review, $56(6), 137-142$.

Chase, R. (1981). The customer contact approach to services: Theoretical bases and practical extensions. Operations Research. 29 (4), 698-705.

Douglas, E. (1962). Size of firm and the structure of costs in retailing, Journal of Business. 25 , April, 158-190.

Fernie, J. (1995). International comparisons of supply chain management in grocery retailing. Service Industries Joumal, 15 (4), 134-147.

Fitzsimmons, J., \& Fitzsimmons, M. (1994). Service management for competitive advantage, New York: McGraw-Hill.

Good, W. (1994). Productivity in the retail grocery trade. Joumal of Retailing. 60 (3), 81-97.

Hackman, J., \& Oldham, R. (1980). Work redesign. Reading MA: Addison-Wesley Publishing Co., 90.

Kroger Annual Report. (1997).

Kurt Salmon Associates. (1993). Efficient consumer response: Enhancing consumer value in the grocery industry. Kurt Salmon Associates.

Lee, L. (1998). Facing superstore saturation, Wal-Mart thinks small. Wall Street Journal, March $25,1998, \mathrm{~B} 1$. 1998, A15.

Levy, M., Zinn, W., \& Bowersox, D. (1989). Measuring the effect of inventory centralization/ decentralization on aggregate safety stock: The 'Square Root Law' revisited. Joumal of Business Logistics. 10 (1), 1-13

McClelland, W. (1962). Economics of the supermarket. The Economic Joumal. 75, 154-170.

Messinger, P., \& Narasimhan, C. (1995). Has power shifted in the grocery industry? Marketing Science. 14 (2), 189-223.

(1997). A model of retail formats based on consumers' economizing on shopping time. Marketing Science. 16 (1), 1-23.

Moinzadeh, K., \& Ingene, C. (1993). An inventory model of immediate and delayed delivery. Management Science. 39 (5), 536-548. 
Ostrofsky, K., \& Cash, J. (1993). Mrs. Fields' Cookies. Case 9-189-056, Cambridge, MA: Harvard Business School.

Ratchford, B., \& Brown, J. (1985). A study of productivity changes in food retailing. Marketing Science, 4 (3), 292-311.

Safeway Annual Report. (1997).

Sansolo, M., \& Garry, M. (1994). Operations: The bottom line on performance. Progressive Grocer, April, 34.

Seshadri, S. (1996). Policy parameters for supply chain coordination. Presentation at the 1996 Multi-Echelon Inventory Conference, Dartmouth College, Hanover, NH.

Shaw, S., Nisbet, D., \& Dawson, J. (1989). Economies of scale in U.K. supermarkets: Some preliminary findings. International Journal of Retailing. 4 (1), 12-26.

Strasser, S., \& Tedlow, R. (1994). Chain stores. Case 9-391-251. Cambridge, MA: Harvard Business School.

Thayer, W. (1991). Four competitors tell how they'd reset the same shelf. Progressive Grocer. 70 (2), 52-60.

Tilley, R., \& Hicks, R. (1971). Economies of scale in supermarkets. Journal of Industrial Economics, $19,1-5$.

Williams, C. (1997). Banks go shopping for customers. The Regional Economist, October, 1213.

Richard Metters is Assistant Professor of Operations Management at the Cox School of Business, Southem Methodist University. He holds a Ph.D. from the University of North Carolina. He has previously published in Journal of Service Research, Production and Operations Management, IIE Transactions, Journal of Operations Management, International Joumal of Production Research, European Journal of Operational Research, Journal of the Operational Research Society, and Production and Inventory Management Joumal.

Michael Ketzenberg is a fourth year doctoral candidate at the Kenan-Flagler Business School, University of North Carolina at Chapel Hill. He holds an M.B.A. from Vanderbilt University and a B.S. from Carnegie Mellon University. His research interests concentrate in supply chain management, value of information, and applied stochastic inventory models. 